\title{
AnOrexia nervosa: UMA REVISÃo
}

\author{
Eder Schmidt $t^{\star}$ \\ Gustavo Ferreira da Mata ${ }^{\star \star}$
}

\begin{abstract}
Resumo
Os autores apresentam uma revisão de alguns pontos de vista com relação à anorexia nervosa. Alinham-se aspectos classificatórios, históricos, clínicos e terapêuticos. Reconhecida como a base para ocorrências místicas na Idade Média, foi entendida como uma apresentação histérica no século XVII, para tornar-se, logo em seguida, objeto das indagações freudianas. Discute-se a anorexia como uma apresentação da estrutura histérica, aqui abordada a partir dos conceitos freudianos sobre histeria, Édipo e feminino, e considerando-se o corpo físico como um mero suporte para articulações simbólicas. Para Freud, a anorexia nervosa seria um quadro pelo qual a histérica exprime sua aversão à sexualidade.
\end{abstract}

Palavras-chave: anorexia nervosa; histeria; feminino.

\section{AnOrexia nervosa: A REVIEW}

\begin{abstract}
The authors present a review of some points regard to anorexia nervosa. Classificatory, historic, clinical and therapeutic aspects are reported. Recognized as the basis for some mystical occurrences at the Middle Ages, it was seen as a hysterical presentation in the seventeenth century, to become object of Freudian questions. It discusses the anorexia as a presentation of the hysterical structure, here boarded from the Freud's concepts on hysteria, Oedipus and femininity, and considering the physical body like a mere support for symbolic articulations. About to Freud, anorexia nervosa is a symptom by which hysterical patient expresses his aversion to sexuality.
\end{abstract}

Keywords: anorexia nervosa; hysteria; feminine.

\footnotetext{
^ Professor Adjunto das Disciplinas de Psicologia Médica e Psiquiatria da Faculdade de Medicina da Universidade Federal de Juiz de Fora.

E-mail:schmidteder@yahoo.com.br

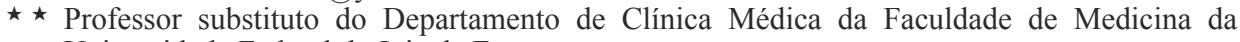
Universidade Federal de Juiz de Fora.

E-mail: phguto@yahoo.com.br
} 


\section{INTRODUÇÃO}

De uma forma geral, consideramos os transtornos alimentares como um conjunto de síndromes cuja característica central é a relação anormal do sujeito com sua alimentação. Dentre eles, a anorexia nervosa se caracteriza pela recusa à alimentação associada a uma alteração na percepção subjetiva da forma e do peso corporais, levando a uma preocupação absolutamente descabida com a possibilidade de ganho ponderal.

“Anorexia”, que remete a ausência de orexis, apetite, descreve, na clínica, um comportamento em que uma exagerada restrição alimentar é adotada no sentido de atingir-se um peso e uma forma corporal suficientemente magra segundo padrões que discordam do senso comum e das variáveis propostas pela medicina. Segundo a Classificação Internacional de Doenças (CID 10), ela seria definida, inicialmente, por um emagrecimento com duas possibilidades de avaliação: uma perda de peso superior a $15 \%$ ou um índice de massa corporal igual ou abaixo de 17,5 (OMS, 1998). Esta perda de peso seria auto-induzida por restrição a alimentos baseada numa distorção da imagem corporal, e associada a um ou mais dos seguintes componentes: vômitos auto-induzidos, purgação auto-induzida, exercício excessivo, anorexígenos ou laxantes. Isso levaria a um transtorno endócrino resultando em amenorréia ou perda da libido em homens e, surgindo antes da puberdade, retardaria a seqüência de eventos que lhe é característica. Ao mesmo tempo, os manuais classificatórios são claros quanto à necessidade de se rever o diagnóstico se esses traços forem secundários a outra patologia vigente.

Embora os critérios diferenciais com o diagnóstico de bulimia nervosa sejam bem definidos, a prática nos apresenta, com alguma freqüência, sintomas mistos dessas duas categorias (FREITAS, 2004).

Em sua forma mais esperada, a anorexia nervosa atinge o sexo feminino em cerca de 95\% das ocorrências, especialmente na faixa etária entre 14 e 17 anos, podendo surgir, tanto precocemente (aos 10 ou 11 anos), quanto tardiamente (após os 23). Trata-se de uma patologia grave, em que a taxa de mortalidade ronda os 5\%, quando associada a diagnóstico e tratamento tardios.

Estima-se uma freqüência de 2 a 4 casos entre mil adolescentes nas sociedades ocidentais, sendo interessante assinalar que este número representa cerca de um quarto dos casos de bulimia nervosa nas mesmas sociedades. Diferente dessa, cuja incidência vem aumentando, os números da anorexia nervosa têm-se mantido constantes, embora os quadros sejam, hoje em dia, melhor diagnosticados (BRUSSET, 2001).

\section{O QUADRO CLÍNICO}

Suspeita-se de uma anorexia nervosa a partir da confluência de quatro fatores: adolescência, conduta alimentar restritiva, emagrecimento e amenorréia. Mesmo após a síndrome já estar em curso, durante algum tempo ela consegue 
ser dissimulada por trás de justificativas que não despertam tanta atenção, sendo, hoje em dia, a mais característica o início de um regime alimentar banal, com a conseqüente limitação quantitativa e qualitativa dos alimentos ingeridos.

Da mesma forma, as perturbações psicológicas que surgem são inicialmente associadas a elementos próprios da adolescência, seja alguma mudança de caráter, irritabilidade, humor depressivo, tendência ao isolamento, ou ainda um uma hiperatividade. De fato, o mais comum é que passem despercebidas as primeiras manifestações próprias do quadro, tanto alimentares quanto psicológicas.

No entanto, mais cedo ou mais tarde, tendo ou não ouvido falar em anorexia nervosa, os pais começam a se incomodar com o regime da filha, tão severo quanto bizarro, tendo sua preocupação agravada pela "bela indiferença" da jovem ante seu progressivo emagrecimento. Para piorar, ao tentarem dissuadi-la de seu propósito, esbarram com uma atitude desafiadora que freqüentemente os surpreende por ser contrastante com um comportamento anterior marcado pela submissão. Ao mesmo tempo em que se tornam alvos de um desprezo indulgente por não partilharem do projeto de redução de peso, os pais vêem o padrão alimentar adquirir um lugar central no cotidiano da jovem, de maneira que os conflitos pré-existentes, tanto individuais quanto familiares, dão lugar a preocupações ou discussões em torno de uma só questão: comer ou não comer.

Como já descrevia Charles Lasègue (1874/2001), cria-se um novo modelo de funcionamento familiar, absolutamente centrado na sintomatologia anoréxica, estabelecendo o vínculo entre a paciente e seu público, dado que ele já considerava central na manutenção de qualquer sintoma histérico. Da mesma maneira, a implicação da família na manutenção dos sintomas era destacada por Charcot, para quem a separação entre a paciente e os familiares era condição para qualquer tratamento de sucesso. Na verdade, fica claro para qualquer observador externo que a insistência dos pais aguça a resistência da anoréxica.

É comum que a família tente associar o quadro a algum fator causal, do tipo má influência, decepções diversas, crises familiares, entre outros; ou ainda, se esforçarem por banalizar aquela atitude, criticando-a como uma mera rebeldia adolescente. Porém, ante qualquer alegação, a paciente sempre explicará sua atitude pelo desejo de emagrecer, ligado a um inconformismo por estar demasiadamente gorda, mesmo quando sua magreza impressiona (BRUSSET, 2007).

Até que se instale uma carência protéica importante, o emagrecimento é relativamente bem suportado e permite, durante um longo tempo, o prosseguimento de uma atividade freqüentemente excessiva. Enquanto isso, as relações sociais tendem a se reduzir, as fantasias empobrecem ou se mostram estereotipadamente centradas no ideal ascético que a anoréxica se impõe; tudo o que se relaciona, ainda que remotamente com a genitalidade ou gravidez é ignorado ou repelido. Compreensivelmente, seus vínculos mais íntimos se restringem a outras anoréxicas de quem ela aceita a assessoria através de sites dedicados às orientações "técnicas" acerca da meta comum. 
Se em um primeiro momento a sensação de controle, não só das exigências, mas também da própria forma do corpo, faz surgir uma euforia, logo se instala a angústia por saber que esta ilusão de onipotência encontra-se sob constante risco. De fato, ao longo de toda a evolução do quadro os episódios bulímicos não são raros, embora culposamente escondidos e compensados por alguma atividade purgativa.

\section{Os SINTOMAS FÍSICOS}

São vários os achados somáticos próprios do quadro anoréxico, sendo que alguns deles podem levar, em casos extremos, ao óbito. Manifestações gastrintestinais como constipação e sensação de plenitude pós-prandial, diminuição da motilidade intestinal poderão estar presentes, alternando com diarréia pelo uso de laxantes. Com freqüência a paciente encontra-se em bradicardia inferior a 60 batimentos por minuto, enquanto que a redução do volume circulante faz com que a hipotensão arterial possa estar presente trazendo tonturas, hipotensão ortostática e síncopes. Falhas na termorregulação podem produzir um aumento da sensibilidade ao frio e episódios de hipotermia virtualmente fatais. Observa-se com o tempo uma diminuição dos caracteres sexuais secundários, assim como uma perda dos contornos do quadril e nádegas. A característica amenorréia deve-se a uma disfunção do hipotálamo, podendo persistir até após a recuperação ponderal. Surge o ressecamento da pele, que perde o brilho e encontra-se por vezes coberta por lanugo, os cabelos tornam-se ralos e muitas vezes quebradiços e avermelhados como é típico nos quadros de desnutrição. As unhas, por sua vez, podem mostrarse quebradiças e com lentificação do crescimento, apresentando-se como um bom campo para o aparecimento e micoses. Em casos extremos, o quadro pode acompanhar-se de catarata, atrofia do nervo óptico e degeneração da retina. O relato de dores ósseas deve ser pesquisado, uma vez que a osteopenia e a osteoporose podem estar presentes causando fraturas (SAITO; FAGUNDES-NETO, 2004).

\section{REVENDO ABORDAGENS}

Historicamente, a sintomatologia anoréxica já há muito tempo é vista como manifestação de alguma desestabilização psicológica primária, e desde o século XIX vem sendo associada à histeria. Textos latinos do século I a.C são as primeiras referências a esse estado, sob o termo fastidium, que significava aversão à comida, enjôo do estômago ou inapetência, existindo, também sob este termo, referências em vários textos do século XVI (CORDAS; CLAUDINO, 2002).

Já a denominação mais específica "anorexia nervosa” surgiu com William Gull a partir de 1873, referindo-se à forma peculiar de doença que afeta principalmente mulheres jovens e caracteriza-se por emagrecimento extremo, cuja "falta de apetite é decorrente de um estado mental mórbido e não a qualquer disfunção gástrica" (PARRY-JONES, 1991, p. 23).

É interessante registrarmos que durante a idade média as práticas de jejum eram freqüentes, sendo associadas tanto a pactos com o demônio, quanto a milagres divinos. Entre os séculos XIII e XVII, há o relato de comportamento anoré- 
xico em mais de 250 santas italianas, no que se conhece como "anorexia sagrada" (BELL, 1985). Triunfando sobre a fome, a dor e a sexualidade, aquelas jovens pretendiam libertar-se das imposições do corpo em favor de metas beatíficas, o que incluía a abolição de quaisquer traços da feminilidade.

Entre todas, a mais famosa é Santa Catarina de Sena, que aos 15 anos, diante de compromissos matrimoniais, iniciou regime de restrição alimentar, preces, autoflagelação e indução de vômito quando obrigada a alimentar-se, vindo a falecer aos 32 anos. Também famosa, a padroeira das Américas e das Filipinas, Santa Rosa de Lima, foi igualmente vítima das complicações de um quadro anoréxico empreendido com intenções de beatitude.

No primeiro relato médico do que viria a ser nomeado anorexia nervosa, Richard Morton, em 1689, descreve o tratamento de uma jovem mulher que, rejeitando qualquer terapêutica, acabou por morrer de inanição. Morton ressaltava que os quadros não eram acompanhados de febre, tosse ou dispnéia, caracterizando-os pela diminuição do apetite, amenorréia, aversão à comida, obstipação, emagrecimento extremo e hiperatividade (CORDAS; CLAUDINO, 2002). Apontava como causas para a doença as violentas paixões, o uso imoderado de destilados e o ar insalubre. Nos textos ele revela sua estranheza e perplexidade ante o desinteresse característico que essas pacientes dispensavam a seu estado de desnutrição, mantendo-se excessivamente animadas apesar do extremo enfraquecimento (COHEN, 2004), referindo-se ao que Freud chamaria mais tarde de "a bela indiferença das histéricas".

Apesar de existirem, desde então, inúmeros relatos na literatura, é na segunda metade do século XIX que a anorexia nervosa surge como uma entidade clínica independente, com sintomatologia bem definida. Em 1873, Charles Lasègue, na França, e William Gull, na Inglaterra, publicaram textos sobre o tema, o primeiro abordando-o como "anorexia histérica", e o segundo como "anorexia nervosa", ambos descrevendo o quadro em sua peculiaridade.

Para Lasègue, entender a patologia era um passo para o esclarecimento da histeria como um todo. Em seu texto De l'Anorexie Hystérique, de 1874, ele se refere à possibilidade de um quadro de plenitude gástrica de origem conversiva ser decorrente, por exemplo, de fantasias secretas em torno de um casamento, sendo o mal-estar, por sua vez, o ponto de partida para uma conduta evitativa frente à alimentação, fazendo surgir, pouco a pouco, o quadro anoréxico em si.

Para William Gull, a "anorexia nervosa", ou apepsia hysterica, evidenciava um quadro semelhante a uma patologia gástrica, possuindo, porém, um fundamento histérico. Propunha como tratamento a alimentação forçada, em espaços regulares de tempo, assinalando que o desejo da paciente não deveria, em nenhuma circunstância, ser levado em consideração, uma vez que a persistência do jejum muitas vezes levava ao óbito (COHEN, 2004). 
Décadas depois de Gull e Lasègue, Jean Martin Charcot apontava como motivação central do quadro a idéia fixa de obesidade, enquanto que para Pierre Janet, o desejo de emagrecer derivava de uma tentativa de retardar a maturidade sexual.

Percebe-se que, desde suas primeiras abordagens médicas, o termo foi associado a uma causa psicogênica, mesmo após sua associação à histeria, cujas hipóteses etiológicas tanto variaram ao longo dos séculos. No entanto, em 1914, a partir da descrição de um caso cuja autópsia revelou a destruição de um dos lobos da hipófise (no que veio a ser conhecido como "Doença de Simmonds" em homenagem a seu relator), a anorexia nervosa passou a ser considerada uma doença com causas puramente orgânicas, associada a aquela condição (COHEN , 2004). Dando seqüência a um ciclo "endócrino" da compreensão das condições de anorexia, Harold Sheehan, em 1930, associou-a à necrose da pituitária no pósparto, no que veio a ser conhecido como "síndrome de Sheehan". Naturalmente, uma vez que se remetiam as causas dos quadros anoréxicos a algum desequilíbrio hormonal, esse passou a ser o foco dos tratamentos (COHEN, 2004).

No entanto, a partir dos anos 40, e à medida que se ampliava a assimilação pela medicina dos conceitos psicanalíticos, a busca de uma compreensão referida à expressão simbólica de conflitos inconscientes ganhava espaço, levando ao abandono gradativo das concepções organicistas sobre a anorexia nervosa. Seguindo os conceitos teóricos vigentes, além das questões orais, algumas hipóteses, em consonância com o modelo psicopatológico da escola inglesa, apontavam para o envolvimento dos núcleos psicóticos do psiquismo e para uma esquizofrenia latente.

Com o incremento das pesquisas em torno dos neurotransmissores, a partir da década de 80 , e especialmente na década de 90 , houve o retorno às hipóteses organicistas, principalmente em referência à função hipotalâmica e à ação de neurotransmissores.

Autores psiquiatras sugerem que a amenorréia característica pode ser causada por um distúrbio primário da função do hipotálamo, possivelmente induzida pelo estresse, e que a subnutrição perpetua a amenorréia, mas não é sua causa principal. Outras teorias envolvem o hipotálamo em um aumento na produção de cortisol, ou questionam um desequilíbrio da serotonina e da noradrenalina. Desde o início deste século, vem sendo desenvolvidas pesquisas sobre uma possível inibição da resposta do hormônio do crescimento à estimulação de receptores específicos (HALMI, 2006).

Em consonância com essas concepções, a medicina traz para o primeiro plano estratégias de tratamento baseadas nos inibidores de recaptação de catecolaminas.

Quanto à psicogênese, a psiquiatria contemporânea, fortemente influenciada pelos conceitos cognitivo-comportamentais, entende que, embora dependente de alguma predisposição genética, a anorexia nervosa exige algo mais para sua compreensão. Sobrepondo-se à hereditariedade, haveria significativas pressões 
exercidas por familiares ou pelo grupo social relativas à aparência, em uma dinâmica familiar marcada por importantes traços obsessivos, depressivos, perfeccionistas e competitivos, havendo por vezes a obesidade entre os membros da família (MORRIS; TWADDLE, 2007; YAGER; ANDERSEN, 2005). Na vigência de conflitos familiares, desafios próprios do desenvolvimento, pressões acadêmicas, e etc. e, principalmente, junto à chegada da puberdade e da adolescência, se daria o desencadeamento do quadro. O abuso sexual, fator habitualmente levantado pela psiquiatria como elemento etiológico, não seria aqui mais importante do que em outras afecções mentais.

Para Duchesne e Almeida (2002), pela ótica da TCC, o distúrbio da imagem corporal é um dos determinantes centrais do quadro, tornando-se, portanto, o objeto privilegiado do tratamento. A anorexia estaria dependente de crenças distorcidas e disfuncionais acerca de peso, formato corporal, alimentação e valor pessoal, incluindo uma relação fechada entre valor pessoal e conformação corporal. Para a anoréxica, a auto-estima estaria dependente da magreza, essa, por sua vez, associada à competência, superioridade e sucesso (DUCHESNE; ALMEIDA, 2002). Quanto a isso, a estratégia seria reduzir as altas expectativas de desempenho que têm essas pacientes, desenvolvendo-se padrões realistas de auto-avaliação, pondo em destaque os sucessos e as qualidades, e levando-as a apoiarem a auto-estima em parâmetros outros que não a aparência (DUCHESNE; ALMEIDA, 2002).

Há, porém, questionamentos quanto à eficácia da TCC, em primeiro lugar pela dificuldade de que o paciente aceite dar início ou, ainda, manter-se em terapia, cuja efetividade, principalmente na estabilização de bons resultados, aumentaria com o emprego paralelo do self-care, quando o paciente administraria sua sintomatologia através de estratégias cognitivo-comportamentais acessíveis on-line ou em CD-ROM (YAGER et al., 2005).

\section{AnOReXia E Histeria}

Abordar, hoje em dia, entidades clínicas pela ótica da psicanálise nos conduz, vez por outra, a impasses, no mínimo, de terminologia. Isso, porque já há algumas décadas, seus fundamentos teóricos vêm sendo desconsiderados pelas classificações vigentes em saúde mental, ao mesmo tempo em que se acentuaram as diferenças no posicionamento nosológico próprio dos manuais classificatórios, CID e DSM, e o da psicanálise, os primeiros limitando-se a um enfoque fenomenológico insuficiente para as pretensões da clínica psicanalítica. É importante lembrarmos que a histeria tornou-se tanto um termo quanto um conceito suprimidos da nosografia psiquiátrica desde o DSM III, de 1980, e que no Brasil, desde a CID X, de 1989, tampouco há lugar para ela na terminologia oficial. Obviamente, pulverizar o quadro histérico em algumas de suas incontáveis apresentações em nada auxilia qualquer clínica que se proponha a abordar o sintoma além de sua manifestação mais externa. Mais do que isso, negar à histeria um nome não a afasta de nosso cotidiano, dentro ou fora dos consultórios. 
Mas, para o teórico psicanalista, o que se poderia apontar na histeria, como próprio de seu funcionamento, aquém de suas diversas possibilidades imaginárias?

A psicopatologia psicanalítica entende que, a partir da dialética edipiana, o psiquismo acabará por adquirir uma organização estrutural definitiva, dependente do posicionamento do sujeito em relação à atribuição fálica, havendo, desde então, uma especificidade e uma predeterminação na manifestação da economia de seu desejo (DOR, 1991). Não sendo nosso objetivo abordar o Édipo, lembramos que a castração, para a menina, implica em perceber e aceitar que a mãe, desejando o desejo do pai, pretende encontrar em seu homem algo, mesmo sabendo que ele não o possui inteiramente (PERRIER, 1992), e que, ao final do Édipo, menino e menina devem aceitar que, se a mãe deseja o pai, é por atribuir a ele a posse do falo, ainda que, para possuí-lo, ele a tenha privado desse atributo. Apresentar-se como aquela que não possui o falo é, portanto, a condição para que a mulher possa desejar e relacionar-se com o homem, e é justamente isto o que a histérica se recusa a aceitar, reivindicando o direito de igualmente possuí-lo (DOR, 1991).

Em função disso, para a histérica, quem sabe sobre seu desejo não é ela, mas aquele a quem vê como possuidor do falo, cabendo-lhe responder ao que ele supostamente deseja. A sujeição ao desejo percebido como alheio torna-se o traço estrutural mais característico da histeria, e, além de seu elemento etiológico mais central, este é o determinante direto de vários aspectos das relações que a histérica estabelece, e também de sua resposta incondicional às expectativas latentes da cultura, a cada momento.

Quanto ao momento que vivemos, tem sido afirmado repetidamente que a anorexia nervosa configura-se como uma de suas patologias mais típicas. Realmente, há algumas décadas lidamos com a valorização do corpo magro, eleito como condição única da beleza e da elegância, paralela à rejeição de qualquer forma física próxima do sobrepeso, muitas das vezes apoiada no saber médico. Ao mesmo tempo, seja por uma pretensa aquisição e manutenção da saúde, seja por motivações ideológicas ou místicas, ou por aqueles mesmos ideais estéticos, a cultura ainda oferece e propõe a adesão a modelos dietéticos alternativos como, por exemplo, as efêmeras dietas da moda, ou os posicionamentos vegetariano ou macrobiótico. Neste cenário, ainda que se discuta a força desses elementos culturais no surgimento da anorexia nervosa, não há como negar que eles, no mínimo, contribuem para mascarar os seus sinais, retardando o diagnóstico e o tratamento.

É, porém, inegável que a possibilidade da cultura construir um sintoma vai estar obrigatoriamente dependente de que se vinculem a ela arranjos estruturais inconscientes, esses sim os reais fundamentos de qualquer sintomatologia. Neste sentido, partindo das observações dos clínicos historicamente ligados à sua descrição vamos buscar os elementos que sustentam a associação da anorexia nervosa à histeria.

Para Lasègue, em seu texto clássico, a anorexia não era mais do que uma das inúmeras faces adotadas por aquela neurose, tão rica em expressões digestivas. Apontando para a estratégia de manipulação implícita nos sintomas, e 
mesmo abstendo-se de maiores considerações etiológicas, é clara a sua hipótese de uma origem psicogênica para a histeria, incluindo a manifestação anoréxica (LASÈGUE, 1874/2001).

Porém, somente após os primeiros textos freudianos a psicogênese da histeria, em todas as suas formas, foi estabelecida de maneira sólida. Quanto à anorexia nervosa, já em 1895, no Rascunho G (sobre a melancolia), Freud (1950 [1892-1899]/1976, p. 222-223) propunha uma etiologia associando-a à anestesia histérica:

A neurose nutricional paralela à melancolia é a anorexia. A famosa anorexia nervosa das moças jovens, segundo me parece (depois de cuidadosa observação), é uma melancolia em que a sexualidade não se desenvolveu. A paciente afirma que não se alimenta simplesmente porque não tem nenhum apetite; não há qualquer outro motivo. Perda do apetite em termos sexuais, perda da libido.

Para ele, a falta de apetite alimentar, portanto, representa para a anoréxica a falta do apetite sexual, e sua ocupação exclusiva com as questões alimentares aponta para a extensão a ser ocupada pelas questões sexuais, se elas pudessem ser consideradas. De fato, este é seu ponto de vista ainda em 1918, no capítulo IX do Homem dos Lobos, referindo-se à neurose em meninas, à época da puberdade, "que exprime a aversão à sexualidade por meio de uma anorexia" (FREUD, 1918[1914]/1976, p. 133).

Partindo de Freud e observando a clínica da anorexia, alguns pontos se destacam: a falta de apetite, a extensão assumida pelas questões alimentares no cotidiano, e o corpo emagrecido que joga por terra toda a possibilidade do apelo erótico, justamente num momento em que a feminilidade desponta e, com toda a sua força e complexidade, compromete aquele corpo. E, que corpo é esse, atingido tão brutalmente, quando não mortalmente, pela anorexia nervosa?

Desde seu início, a teoria freudiana recusa ao ser humano um corpo natural, biológico. Em seu aspecto anatômico, o corpo é, para a psicanálise, um mero suporte de representações simbólicas, em maior medida, inconscientes, o que permite que uma conflitiva psíquica nele produza efeitos totalmente desvinculados de quaisquer determinantes orgânicos. Já nos Estudos sobre a histeria (FREUD, 1895/1976) a noção de corpo se desprendia de sua concepção anátomo-fisiológica, apresentando-se como um palco onde o conflito inconsciente era encenado. A conversão histérica transforma o corpo em veículo de uma mensagem que deve permanecer inconsciente. Na anorexia nervosa, então, o que se tem é um corpo cuja expressão remete a algo que se refere à feminilidade e, ao mesmo tempo, à necessidade de sabotá-la.

$\mathrm{Na}$ teoria freudiana, assim como o corpo, a identidade sexual não possui, absolutamente, qualquer determinação natural, estando a questão fálica no centro da organização do desejo, masculino ou feminino. Como vimos acima, alcançar o feminino, para aceder à feminilidade, implica, obrigatoriamente, em que a me- 
nina, partindo do Édipo e da castração, admita sua falta para poder identificar-se com a mãe e dirigir seu desejo para o suposto detentor do falo na expectativa de receber dele a satisfação (FREUD, 1933/1976).

O desejo parte, portanto, da assunção da falta, o que, em um jogo de atribuições mútuas, leva cada um a supor o outro como quem possui ou é o falo (PERRIER, 1992). Para desejar e dirigir-se ao homem, a mulher é obrigada a assumir que é ele, e não ela, quem possui o falo, e é justamente isto o que a histérica se recusa a aceitar (DOR, 1991), ainda que, para tanto, se mostre indiferente ao desejo.

Podemos, então, entender que a questão alimentar representa a posição da anoréxica ante o desejo e à falta, levando-a a deformar seu corpo de maneira a embaçar nele os atributos tradicionalmente associados ao feminino. Recusar a feminilidade é o artifício para negar a diferença sexual que, pela via da cultura, a ela conduz, e admitir em si o corpo feminino implica em reconhecer-se privada do falo aceitando receber de um homem a satisfação como mulher.

Como nos demais sintomas histéricos, em sua indiferença, a anoréxica triunfa e pretensamente se impõe ao que a todos submete, o desejo, e ao recusar este preceito básico da condição humana, nega a insatisfação para, acima de tudo, negar a falta. Isso leva Glaucinéa Lima e Beatriz Gutierra (2005) a afirmarem que, para a anoréxica, "o desejo é desejo de nada".

Experiente observador dos fenômenos clínicos Lasègue, já em 1873, ressaltava na atitude da anoréxica o prazer do autocontrole e do controle do outro. Auto-erótica, ela se basta, recusando-se ao social e ao sexual, laços que só se estabilizam na vigência da castração.

\section{O TRATAMENTO DO CORPO FÍSICO}

Em primeiro lugar, é importante assinalar que a anorexia nervosa se apresenta em graus variados de comprometimento, e que a gravidade da neurose não está diretamente ligada ao grau de emagrecimento, de maneira que, às vezes, um quadro de severa restrição alimentar e importantes restrições no plano afetivo-erótico pode ocorrer paralelo a um sucesso no campo profissional.

De maneira geral, devemos considerar o tratamento da anorexia nervosa constando de quatro abordagens:

a) a recuperação nutricional que, por sua vez, com freqüência necessitará de

b) abordagem psicofarmacológica visando uma suspensão mais rápida da recusa ao alimento, o que não implica em uma rearticulação da conflitiva inconsciente individual ou familiar que sustenta a sintomatologia o que, exigirá

c) a psicanálise e

d) a terapia familiar, ou de outros membros da família. 
Como a anorexia tem a propriedade de despertar nos pais e cuidadores uma considerável angústia, pode surgir a tentação de, autoritariamente, prescrever-se uma hospitalização precoce como uma forma de coação no sentido da retomada de um peso ideal arbitrado (BRUSSET, 2001). A hospitalização pode, ou não, ser necessária, mas, embora a retomada ponderal e a suspensão da amenorréia sejam metas óbvias, não podem se constituir como os pontos finais da proposta terapêutica, uma vez que, sem a rearticulação das questões histéricas subjacentes, estas aquisições tendem a ser efêmeras e as recidivas freqüentes.

Já quanto à psicanálise, é interessante lembrar que o próprio Freud (1905[1904]/1976, p. 248) em "Sobre a Psicoterapia", adverte: "Não se deve recorrer à psicanálise quando se trata de eliminar com rapidez fenômenos perigosos, como, por exemplo, a anorexia histérica”. Em outras palavras, a expectativa de que o tratamento psicanalítico conduza ao rearranjo da conflitiva fundamental não permite que se prescinda dos demais itens da estratégia terapêutica. Nesse sentido, a supressão do quadro manifesto não é por si só, considerada critério para a suspensão da psicanálise ou de qualquer modalidade de psicoterapia que venha a ser empregada.

A patologia pode, ainda, evoluir, embora em uma minoria dos casos, sob forma de patologia depressiva, neurótica ou psicótica. A morte pode suceder, de forma um tanto rara, no caso do tratamento ser iniciado tardiamente.

Do ponto de vista farmacológico, as drogas de escolha são os inibidores seletivos de recaptação da serotonina, embora seja necessário considerar o risco de que alguns deles, como a fluoxetina ou o citalopram, apresentem, freqüentemente uma propriedade anorexígena como efeito colateral. Os antidepressivos tricíclicos, como, por exemplo, a amitriptilina, apesar de proporcionarem freqüente ganho ponderal, tem seu risco de efeitos cardíacos aumentados em pacientes com tamanha deficiência nutricional e desequilíbrio eletrolítico. Os benzodiazepínicos estão contra-indicados, uma vez que seu considerável potencial aditógeno é ainda maior nessas circunstâncias (FREITAS, 2004).

A rigor, o comprometimento da saúde dessas pacientes faz com que quaisquer intervenções farmacológicas ou mesmo nutricionais sejam objetos de preocupação e exijam apurada avaliação clínica.

\section{A hospitalização}

São considerados parâmetros clínicos para a hospitalização, ganho menor do que $75 \%$ do peso esperado nas tentativas de recuperação nutricional, índice de massa corpórea abaixo da faixa de 13 a $14 \mathrm{~kg} / \mathrm{m}^{2}$; presença de alterações como hipotensão arterial grave, bradicardia, hipotermia, hipoglicemia e hipocalemia, além de alterações indicativas de ameaça imediata à sobrevivência do paciente, como disfunção cardíaca, renal ou hepática, sintomas de desidratação e desnutrição grave e a necessidade de alimentação por sonda 
nasogástrica. Deve-se considerar que hospitalizações repetidas, com realimentação forçada, são indicativos de uma evolução psicológica desfavorável (SAITO; FAGUNDES-NETO, 2004).

Ao se avaliar a propriedade da internação são também observados determinantes de ordem psíquica, desde falta de adesão ao tratamento ambulatorial até quadros psiquiátricos, como depressão grave, principalmente associada a risco suicídio ou auto-agressão.

Outras vezes, opta-se pela internação de pacientes que apresentem alguma dificuldade objetiva para o acesso aos ambulatórios, ou daqueles cuja família, por qualquer razão, não se apresenta com disponibilidade para colaborar com o tratamento.

\section{Prognóstico}

Se, quanto mais estreita a ligação do quadro à crise da adolescência, melhor tende a ser o prognóstico, o pior prognóstico é associado ao surgimento tardio do quadro, ao retardo no diagnóstico com conseqüente retardo na intervenção, bem como a uma problemática familiar marcada pela gravidade e pela cristalização dos conflitos. No entanto, de maneira geral, a proporção de pacientes que se recupera completamente é pequena, e um terço deles continua a ter problemas com a imagem corporal, sendo que $40 \%$ adquirem sintomas de bulimia ou dificuldades psiquiátricas diversas (FREITAS, 2004).

A taxa de mortalidade associada à anorexia nervosa é em torno de $5 \%$, principalmente devido a doenças cardíacas e suicídios (SAITO; FAGUNDES-NETO, 2004).

\section{REFERÊNCIAS:}

BELL R. M. Holy anorexia. Chicago: University of Chicago Press, 1985.

BREUER, J.; FREUD, S. Estudos sobre a histeria (1895). In: . Obras Psicológicas Completas de Sigmund Freud. Rio de Janeiro: Imago. 1976. Edição Standard. v. II, p. 13-59.

BRUSSET, B. Les troubles du comportement alimentaire. Observatoire de l'enfance en France, Paris, n. 36, janv. 2001. Disponível em: <http://www. observatoiredelenfance.org/IMG/pdf/Numero_36_-_Les_troubles_du comportement_alimentaire.pdf $>$. Acesso em: 20 out. $200 \overline{7}$.

COHEN, B. J. Lecture 18: Eating disorders. University of Virginia Health System, 2004. Disponívelem: $<$ http://www.healthsystem.virginia.edu/internet/psychtraining/seminars/eating-disorders-1-30-04.pdf>. Acesso em: 20 out. 2007. 
CORDAS, T. A.; CLAUDINO, A. Transtornos alimentares: fundamentos históricos. Revista Brasileira de Psiquiatria, São Paulo, v. 24, supl. 3, p. 03-06, dez. 2002.

DOR, J. Estruturas e clínica psicanalitica. Rio de Janeiro: Taurus-Timbre, 1991. p. 21-22.

DUCHESNE, M.; ALMEIDA, P. E. M. Terapia cognitivo-comportamental dos transtornos alimentares. Rev. Bras. Psiquiatr., São Paulo, v. 24, supl. 3, p. 49-53, dez. 2002.

FREITAS, S. Transtornos Alimentares: Introdução, diagnóstico, epidemiologia e etiologia. In: BRASIL, M. A. A.; BOTEGA, N. J. (Org.). Programa de Educação Continuada ABP Brasil. Rio de Janeiro: Guanabara Koogan, 2004. v. 1, p. 196-204.

FREUD, S. Extratos dos documentos dirigidos a Fliess (1950 [1892-1899]). In: . Obras Psicológicas Completas de Sigmund Freud. Rio de Janeiro: Imago. 1976. Edição Standard. v. I. p. 243-377.

. História de uma neurose infantil (1918 [1914]). In: - Obras

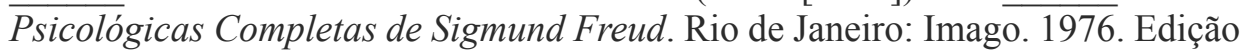
Standard. v. XVII. p. 19-151.

- Feminilidade. Novas Conferências Introdutórias sobre Psicanálise (1933). In: . Obras Psicológicas Completas de Sigmund Freud. Rio de Janeiro: Imago. 1976. Edição Standard. v. XXII, p. 139-165.

. Sobre a psicoterapia (1905[1904]). In: - Obras Psicológicas Completas de Sigmund Freud. Rio de Janeiro: Imago, 1976. Edição Standard. v. VII.

HALMI, K. A. Transtornos da alimentação: anorexia nervosa, bulimia nervosa e obesidade. In: HALES, R.; YUDOFSKY, S. Tratado de psiquiatria clínica. Porto Alegre: Artmed, 2006. p. 941-962.

LASĖGUE, C. De l'Anorexie Hystérique (1874). Relatos de la Clínica, Buenos Aires, n. 2, nov. 2001. Disponível em: <http://www.psicomundo.com/relatos/ relatos2/Lasegue-anorexie.pdf>. Acesso em: 20 out. 2007.

LIMA, G. G.; GUTIERRA, B. C. C. Anorexia: fome de nada. In: SIMPOSIO INTERNACIONAL DO ADOLESCENTE, 1., 2005, São Paulo. Anais eletrônicos... Disponível em: <http://www.proceedings.scielo.br/scielo. php?script $=$ sci_arttext\&pid=MSC0000000082005000200037\&lng=pt\&nrm=ab n>. Acesso em: 20 out. 2007. 
MORRIS, J.; TWADDLE, S. Anorexia nervosa. BMJ, n. 334, p. 894-898, Apr. 2007. doi:334:894-8: 10.1136/bmj. 39171.616840.BE.

ORGANIZAÇÃO MUNDIAL DE SAÚDE. CID-10: Classificação Estatística Internacional de Doenças. Porto Alegre: Artes Médicas, 1998.

PARRY-JONES, B. Historical terminology of eating disorders. Psychol Med, v. 21, n. 1, p. 21-28, Feb 1991.

PERRIER, F. Estrutura Histérica e diálogo analítico. In: clínica psicanalítica. São Paulo: Escuta, 1992. p. 73-89. Ensaios de

SAITO, J. T.; FAGUNDES-NETO, U. Anorexia Nervosa. The Electronic Journal of Pediatric, Gastroenterology, Nutrition and Liver Diseases, São Paulo, v. 8, n. 3, set. 2004. Disponível em: <http:// www.e-gastroped.com.br/sept04/anorexianervosa.htm>. Acesso em: 20 out. 2006.

YAGER, J.; ANDERSEN, A. E. Anorexia Nervosa. The New England Journal of Medicine, v. 353, n. 14, p. 1481-1488, Oct. 2005. Disponível em: <http://content. nejm.org/cgi/content/extract/353/14/1481>. Acesso em: 05 abr. 2006.

YAGER, J. et al. American Psychiatric Association: Practice Guideline for the Treatment of Patients With Eating Disorders. 2nd. ed. Am J Psychiatry, 2005.

Recebido em: dezembro de 2007

Aceito em: novembro de 2008 